Int. J. Morphol.,

33(2):638-646, 2015.

\title{
Effects of c-FLIPL Knockdown in Cervical Uterine Carcinoma Cell Lines
}

\author{
Efectos de la Inhibición de C-Flipl en Líneas Celulares de Cáncer de Cuello Uterino
}

\author{
Carmen G. Ili"; Priscilla Brebi*; Patricia Garcia**; Pamela Leal ${ }^{* * * *}$; Jaime Lopez; Oscar Tapia*; \\ Pablo Letelier**; Helga Weber*; Jonathan Castillo* \& Juan C. Roa**
}

ILI, C. G.; BREBI, P.; GARCIA, P.; LEAL, P.; LOPEZ, J.; TAPIA, O.; LETELIER, P.; WEBER, H.; CASTILLO, J. \& ROA, J. C. Effects of c-FLIPL knockdown in cervical uterine carcinoma cell lines. Int. J. Morphol., 33(2):638-646, 2015.

SUMMARY: Overexpression of Short and Raji variants of Cellular FLICE-like inhibitory protein (c-FLIP) is capable of inhibiting apoptosis, while the function of the Long isoform depends of c-FLIPL concentration in cells. The aim of this study was to determine the effects of c-FLIPL knockdown in cervical cell lines. SiHa, C-4I and C-33A cervical cancer cell lines were analyzed. c-FLIPL level expression was determined by quantitative real-time PCR and western blotting. c-FLIPL was transiently downregulated by siRNA. The effects of knockdown of c-FLIPL on cell viability, proliferation and apoptosis were assessed by comparing with scrambled siRNAtransfected cells. SiHa and C-4I c-FLIPL knockdown cells showed increased viability compared with scrambled siRNA-transfected cells $(\mathrm{P}<0.05)$, while $\mathrm{C}-33 \mathrm{~A}$ cells did not show significant differences. Ki-67 and PCNA immunocytochemistry was performed to evaluate proliferation on these cervical cancer cell lines. SiHa cells with c-FLIPL knockdown showed elevated expression of Ki-67 protein compared with their scrambled counterparts $(\mathrm{P}<0.0001)$, while C-33A c-FLIPL knockdown cells showed a significantly lower in PCNA expression $(\mathrm{P}<0.01)$ compared with control. All three c-FLIP-transfected cell lines showed a higher level of apoptosis compared with their scrambled controls. Our results suggest that c-FLIPL could have effects in proliferation and apoptosis in cervical cancer cell lines.

KEY WORDS: Apoptosis; Proliferation; Cervical cancer; siRNA; c-FLIPL.

\section{INTRODUCTION}

Apoptosis is a fundamental process for development and the immune response of multicellular organisms (Yang, 2008). A cell starts programmed cell death when DNA damage occurs, thereby activating the intrinsic pathway of apoptosis or when the extrinsic pathway is activated by external signals, such as the Fas ligand (FasL) or TRAIL (tumor necrosis factor-related apoptosis-inducing ligand) (Wang, 2001). External stimulus allows oligomerization of the Fas and TRAIL family receptors and the formation of DISC (death-inducing signaling complex). In the extrinsic pathway, procaspase-8 is cleaved by DISC and converted to caspase-8, which subsequently initiates apoptosis (Bénéteau et al., 2007; Yang).

Cellular FLICE-like inhibitory protein (c-FLIP), also known as CFLAR (CASP8 and FADD-like apoptosis regulator), is a catalytically inactive caspase- $8 / 10$ homolog that interferes with the efficient formation of DISC (Irmler et al., 1997). The c-FLIP gene has $48 \mathrm{~kb}$ and at least 14 exons (Djerbi et al., 2001). Studies have described 13 distinct splice variants of c-FLIP mRNA, but only three protein isoforms have been detected: c-FLIPL (Long) of $55 \mathrm{kDa}$, cFLIPS (Short) of $26 \mathrm{kDa}$ and c-FLIPR (Raji) of $24 \mathrm{kDa}$ (Budd et al., 2006; Yang). c-FLIPL isoform has a structure that is similar to procaspase- 8 but does not contain a catalytic domain at the C-terminus (Budd et al.; Bénéteau et al.). The caspase- 8 and c-FLIP genes are located in chromosome 2 in close proximity to each other. Therefore, the similarity between caspase- 8 and c-FLIP could derive from a duplication of the caspase- 8 gene (Budd et al.).

\footnotetext{
Laboratorio Patología Molecular, Departamento de Anatomía Patológica, Facultad de Medicina, CEGIN-BIOREN, Universidad de La Frontera, Temuco, Chile.

** Departamento de Patología, Escuela de Medicina, Pontificia Universidad Católica de Chile, Santiago, Chile.

*** Escuela de Ciencias de la Salud, Universidad Católica de Temuco, Temuco, Chile.

***** Center of Genetic and immunological Studies (CEGIN) and Scientific and Technological Bioresource Nucleus (BIOREN). Universidad de La Frontera, Temuco, Chile.

Financiamiento: Esta investigación fue financiada por: Beca de Apoyo de Tesis Doctoral N²4090166 (CONICYT), Proyecto CORFO-INNOVA $\mathrm{N}^{\circ} 12 \mathrm{IDL} 2-18157$, Proyecto CORFO N 09 CN14-5960 (CEGIN), Fondap CONICYT ACCDIS 15130011 y FONDECYT Postdoctoral N³130630.
} 
The functions of c-FLIPS and c-FLIPR have been well established; both isoforms can block the extrinsic apoptotic pathway by inhibiting procaspase- 8 activation in DISC (Krueger et al., 2001). However, the function of cFLIPL still remains unclear. When c-FLIPL is overexpressed, it has an anti-apoptotic function very similar to that of cFLIPS; however, c-FLIPL can also be a pro-apoptotic molecule at low concentrations (Krueger et al., 2001; Chang et al., 2002; Sharp et al., 2005). Although c-FLIPL has been described in most studies as an inhibitor of caspase- 8 activation, some authors have suggested that c-FLIP can activate caspase- 8 .

The overexpression of c-FLIP has been linked to carcinogenesis because c-FLIP inhibits apoptosis and causes treatment resistance of tumor cells (Yang). Several neoplasms have shown an altered expression of c-FLIP: colorectal carcinoma, gastric carcinoma, pancreatic carcinoma, Hodgkin's lymphoma, chronic lymphocytic leukemia, melanoma, endometrial carcinoma, bladder uroepithelial carcinoma, prostatic carcinoma (Yang) and, recently, cervical uterine carcinoma (Wang et al., 2007; Ili et al., 2013). The aim of this study was to characterize c-FLIPL knockdown effects in cervical uterine cell lines.

\section{MATERIAL AND METHOD}

Cell lines. Four cell lines were used in this study. ECT1 E6/ E7 (transformed normal squamous epithelial cell line) and $\mathrm{SiHa}$ (squamous cell carcinoma, containing integrated HPV 16 genome) cells were generously provided by Dr. David Sidransky (Johns Hopkins School of Medicine, Baltimore, USA). C-4I (cervical carcinoma containing integrated HPV 18 genome) and C-33A (cervical carcinoma, negative for HPV DNA and RNA) cells were purchased from the American Type Culture Collection (ATCC). ECT1 E6/E7 was cultured in keratinocyte-serum-free medium 1X (Gibco) supplemented with $2.5 \mathrm{mg}$ recombinant human epidermal growth factor (EGF, Gibco), $25 \mathrm{mg}$ bovine pituitary extract (Gibco) and $0.4 \mathrm{mM}$ calcium chloride. SiHa and C-33A cell lines were cultured in Advanced MEM medium (Gibco) supplemented with $25 \mathrm{mM} \mathrm{L}$-glutamine and 5\% FBS. C-4I cells were grown in Waymouth's MB 752/1 medium (Gibco) supplemented with $10 \%$ FBS. All media were supplemented with $100 \mathrm{U} / \mathrm{mL}$ penicillin and $100 \mathrm{mg}$ streptomycin (Thermo Scientific). All cell lines were incubated at $37{ }^{\circ} \mathrm{C}$ in a humidified atmosphere containing $5 \% \mathrm{CO}_{2}$ and subcultured during the logarithmic growth phase.

siRNA transfection. The cervical cancer cell lines were transfected with a total of 100 pmol of CFLAR (c-FLIP)
Silencer Select Pre-designed siRNA (siRNA ID: s229912, Ambion) or Silencer Select Negative Control \#1 (Ambion) using Lipofectamine 2000 (Invitrogen). c-FLIP siRNA sequences were 5' -GAAAAAUGCCUAAAGAACAtt-3' (sense) and 5'-UGUUCUUUAGGCAUUUUUCta-3' (antisense). Cells were seeded $24 \mathrm{H}$ before transfection in flasks or plates using antibiotic-free medium. Cells at 30$50 \%$ of confluence were used for transient transfection. Briefly, Lipofectamine 2000 was diluted in Opti-MEM I reduced serum medium (Gibco) and incubated for $5 \mathrm{~min}$ ( $1.5 \mathrm{~mL}$ per well in a 24 -well plate). In a separate tube, siRNA c-FLIP or Scrambled (Negative control) were diluted in OptiMEM I reduced serum medium (Gibco). Both tubes were combined and incubated for $20 \mathrm{~min}$ to obtain a siRNALipofectamine complex that was finally added to the cells. All analyses were performed $48 \mathrm{~h}$ after cellular transfection unless stated otherwise. The success of the transfection was measured through quantitative real-time PCR, western blotting or pCMV6-AC-GFP (Origene) co-transfection of cells (fluorescence microscopy).

RNA extraction and quantitative real-time PCR. Relative mRNA expression was analyzed by real-time PCR. Cells at 80-90\% confluence were washed with cold PBS, and total cellular RNA was isolated using TRIzolTM reagent (Ambion by Life Technologies). After $20 \mathrm{~min}$ at room temperature, lysates were centrifuged at $13,000 \mathrm{rpm}$ for $20 \mathrm{~min}$ at $4{ }^{\circ} \mathrm{C}$. The supernatants were transferred to fresh tubes, and isopropanol was added to precipitate RNA. After overnight incubation, tubes were centrifuged at $13,000 \mathrm{rpm}$ for $15 \mathrm{~min}$ at $4{ }^{\circ} \mathrm{C}$. Pellet was washed twice with $75 \%$ ethanol and resuspended in $30 \mathrm{~mL}$ diethylpyrocarbonate (DEPC)-treated water. Total RNA was quantified using a NanoDrop spectrophotometer, and its integrity was evaluated by electrophoresis on a denaturing agarose gel. Total RNA (500 ng) was reverse transcribed using the AffinityScript QPCR cDNA Synthesis Kit (Agilent Technologies, Inc.). cDNA was subsequently amplified by PCR using the Brilliant II SYBR Green qPCR master mix on a Mx3000p Real-Time PCR system (Agilent Technologies, Inc.). c-FLIP and GAPDH primers were designed as follows: c-FLIP: forward, 5'AGAGTGCTGATGGCAGAGATTGGT-3'; reverse, 5'TCTCCAACTCCACAAGGTCCA-3'; GAPDH: forward 5'-AGCTACATCGCTCAGACAC-3'; reverse 5'GCCCAATACGACCAAATCC-3'. The primer's efficiency was calculated after calculating a calibration curve using logarithmic cDNA dilution. Relative fold levels were determined using the $2^{-\triangle \Delta C T}$ method with GAPDH as a housekeeping control.

Western blotting assay. Cells at $80-90 \%$ confluence were collected, washed with cold PBS and resuspended in RIPA buffer (Sigma) containing phenylmethylsulfonyl fluoride 
(PMSF) and protease and phosphatase inhibitor cocktail (Thermo Scientific). The whole cell lysate was clarified by centrifugation at $8,000 \mathrm{~g}$ for $10 \mathrm{~min}$ at $4{ }^{\circ} \mathrm{C}$. The total protein concentration was determined by Pierce BCA protein assay (Thermo Scientific). Equal amount of proteins $(20 \mu \mathrm{g})$ was resolved by SDS-PAGE in $4-12 \%$ NuPAGE Bis-Tris Precast Gels (Novex by Life Technologies) and transferred to a polyvinylidene difluoride membrane (PVDF, Thermo Scientific). The membranes were blocked with 5\% fat-free milk in 1X Trisbuffered saline containing $0.05 \%$ Tween (TBS-T) for $1 \mathrm{~h}$ at room temperature and blotted with diluted primary antibody at $4{ }^{\circ} \mathrm{C}$ overnight. Membranes were then washed with $1 \mathrm{X}$ TBS-T and incubated with secondary antibody for $1 \mathrm{~h}$ at room temperature. After washing, bands were visualized using SuperSignal West Pico chemiluminescent reagent (Thermo Scientific) and photographed with Amersham Hyperfilm ECL autoradiography film (GE Healthcare Biosciences). Antibodies and dilutions were as follows: 1:1,000 FLIP rabbit $\mathrm{pMb}$ (Cell Signaling), 1:5,000 B-actin (13E5) rabbit mAb (Cell Signaling) and 1:10,000 or 1:20,000 goat anti-rabbit IgG-HRP (Santa Cruz Biotechnology).

Cellular viability assay. A cell viability assay was performed using the CellTiter 96® Aqueous One Solution Cell Proliferation Assay Kit (Promega). Cells were seeded in 96-well plates in triplicate at a density of 1000 cells per well. After 4, 24, 48, and $72 \mathrm{~h}$, the MTS reactive was added to each well $(20 \mathrm{~mL})$. After an incubation of $1 \mathrm{~h}$, the absorbance was measured at $490 \mathrm{~nm}$ in a multi-well plate reader spectrophotometer (Autobio Labtec Instruments Co. Ltd.). The absorbance of cells incubated for $4 \mathrm{~h}$ was used as reference. After $24 \mathrm{~h}$ of culture, cells were transfected with c-FLIP or scrambled siRNA.

Proliferation assay by immunocytochemistry. An immunocytochemistry assay of Ki-67 and PCNA (proliferating cell nuclear antigen) proliferation markers was performed. Cells at a density of 10,000 cells were seeded on coverslips coated with poly-1-lysine in 24-well plates. Cells were transfected at $24 \mathrm{~h}$ of culture, with cFLIP or scrambled siRNA. After $48 \mathrm{~h}$ of incubation, cells were washed three times with 1 X PBS and fixed with cold acetone for $10 \mathrm{~min}$. After washing with $1 \mathrm{X}$ PBS, endogenous peroxidase was blocked with hydrogen peroxide for $10 \mathrm{~min}$. Cells were then washed and incubated for $1 \mathrm{~h}$ at room temperature with 1:500 monoclonal antiKi-67 (Bio SB) or $4{ }^{\circ} \mathrm{C}$ overnight with 1:2,000 polyclonal anti-PCNA(Abcam). Then, coverslips containing the cells were washed and incubated for $30 \mathrm{~min}$ with Mouse/Rabbit Polidetector HRP label (Bio SB). Labeling was detected with the DAB-chromogen system (Dako) according to the manufacturer's protocol. All coverslips were counterstained with Harris hematoxylin, dehydrated, and mounted. A semi-quantitative scale was used to score $\mathrm{Ki}-67$ and PCNA reactivity in cells according to the labeling intensity $(0=$ absent; $1=$ weak; $2=$ moderate; $3=$ strong $)$ and the percentage of positive cells $(0 \%-100 \%)$. Subsequently, a final score was obtained by multiplying the percentage of positive cells by the intensity (Maximum Score: 300) (Charafe-Jauffret et al., 2004). The scores were independently obtained by two of the authors (O.T. and J.C.R.). The inter-observer differences were $<4 \%$, and the average of the two values was obtained.

TUNEL-based assay. Apoptosis was measured using TUNEL assay and flow cytometry. Briefly, 200,000 cells were seeded in $25 \mathrm{~mm}^{3}$ flasks. After $24 \mathrm{~h}$ of incubation, cells reached 30 to $50 \%$ confluence and transfection with c-FLIP or scrambled siRNA was performed. Then, cells were incubated for another $48 \mathrm{~h}$ before they were trypsinized and pelleted. Pellets were washed three times and resuspended in $100 \mathrm{~mL}$ of a freshly prepared fixation solution ( $2 \%$ paraformaldehyde) to form a cell suspension. To avoid extensive clumping of cells, the incubation with the fixation solution was performed on a shaker for $1 \mathrm{~h}$ at room temperature. A permeabilization solution $(0.1 \%$ Triton $\mathrm{X}-100$ in $0.1 \%$ sodium citrate) was added to the cells after washing. Then, cells were placed on ice for 2 min. After washing, the cells were labeled using an In Situ Cell Death Detection Kit, Fluorescein (Roche) to determinate DNA fragmentation in cell lines. Briefly, the labeling solution and enzyme solution were combined to obtain a TUNEL reaction mixture, which was added to the cells. Labeled cells were filtered $(100 \mathrm{~mm})$ and counted by flow cytometry (FACS Canto II, Becton Dickinson) in the wavelength range of 515 to $565 \mathrm{~nm}$. Autofluorescence, negative and positive controls were included in the assay to analyze the results and establish cell populations. The autofluorescence control corresponds to fixed and permeabilized cells without label to measure size and autofluorescence. The positive control corresponds to cells treated with DNase to degrade DNA. The negative control corresponds to cells labeled only with the labeling solution. Transfected cell populations were compared with TUNEL-based assay controls to establish cells with DNA fragmentation.

Statistical analysis. All experiments were repeated at least three times and performed in triplicate. Statistics analyses were performed using GraphPad Prism 5.0 software. Associations between variables were examined using twoway ANOVA followed by a Bonferroni post-test, MannWhitney test or Student's t-test. P values $<0.05$ were considered statistically significant. 


\section{RESULTS}

c-FLIPL expression in cervical carcinoma cell lines. cFLIPL was found overexpressed at transcriptional level in SiHa compared with ECT1 E6/E7 (P<0.001). Whereas, no significant differences were observed in the relative mRNA expression of c-FLIP in C-4I and C-33A cells compared with normal cells (Fig. 1). Western blot analysis showed no significant differences in protein expression among wildtype cell lines. Under our experimental conditions, just cFLIP long isoform was detected. All three cervical cancer cell lines were successfully transfected with siRNA c-FLIP. Transcription of c-FLIP was repressed in more than $80 \%$ of cells transfected with c-FLIPL siRNA compared with scrambled control after $48 \mathrm{~h}$ of incubation. Western blot analysis also showed a partial or complete decrease of cFLIP protein in knockdown cells (Fig. 2).

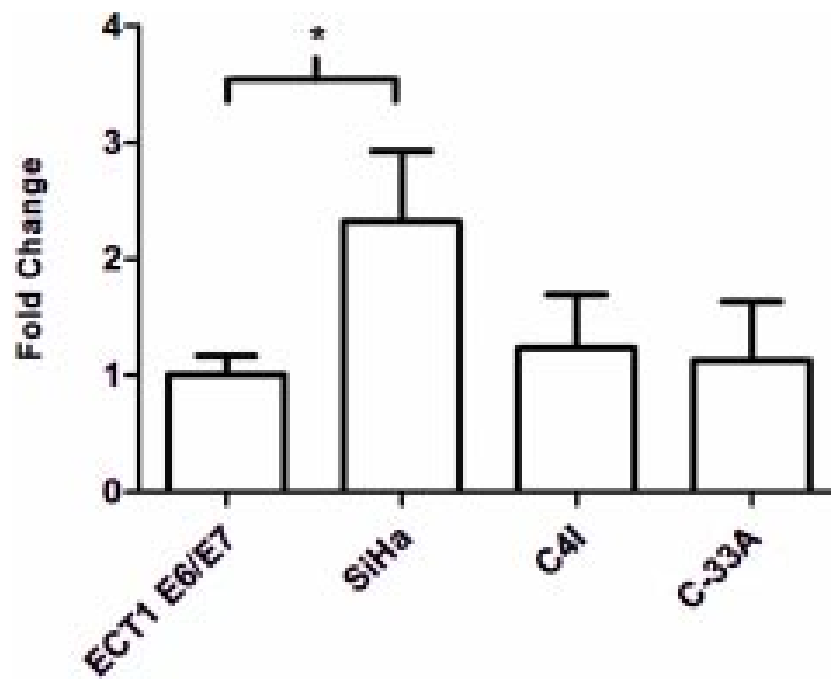

Fig. 1. c-FLIPL mRNA expression level in cervical cancer cells lines by quantitative PCR, compared with an immortalized squamous cervical epithelial cell line. GAPDH was used as normalizer gene. SiHa seems to have a higher expression of cFLIPL mRNA than normal and others cervical cancer cell lines.
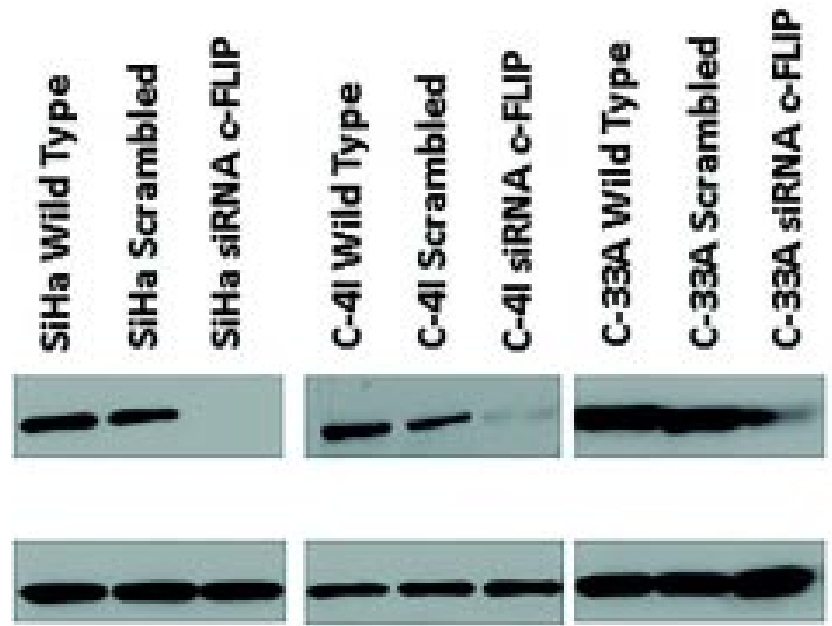

c-FLIP knockdown affects cervical cancer cell viability. $\mathrm{SiHa}$ and C-4I cell lines transiently transfected with siRNA c-FLIPL showed a higher viability compared with their respective scrambled control cells. In both cells lines, differences could be observed starting on second day, but statistically significant differences were observed from second day in C-4I and fourth day in SiHa. In C-33A, no significant differences between c-FLIPL siRNA and scrambled-transfected C-33A cells were observed (Fig. 3).
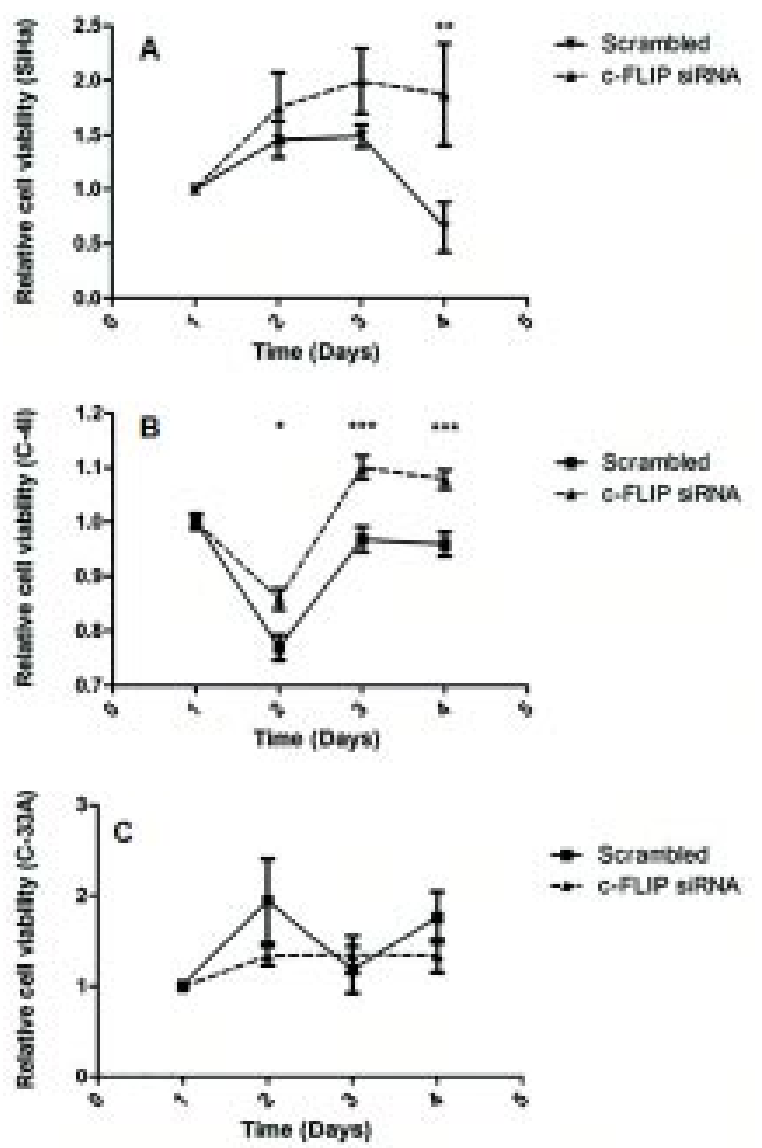

Fig. 3. In vitro cell viability of c-FLIPL siRNA transfected cells compared with scrambled, measured using MTS assay. (A) SiHa c-FLIPL knockdown versus scrambled; (B) C-4I c-FLIPL knockdown versus scrambled; (C) C-33A c-FLIPL knockdown versus scrambled. $*=\mathrm{P}<0.05, * *=\mathrm{P}<0.01, * * *=\mathrm{P}<0.001$ as compared with control; 2-way ANOVA followed by Bonferroni post-test.

c-FLIP 58 kDa

\section{Beta actin $45 \mathrm{kDa}$}

Fig. 2. Western blot analysis of cFLIPL total protein expression in cells transfected with c-FLIPL siRNA compared with scrambled transfected cells and wild type cells. siRNA transient knockdown of c-FLIPL in vitro was effective in cervical cancer cell lines. 

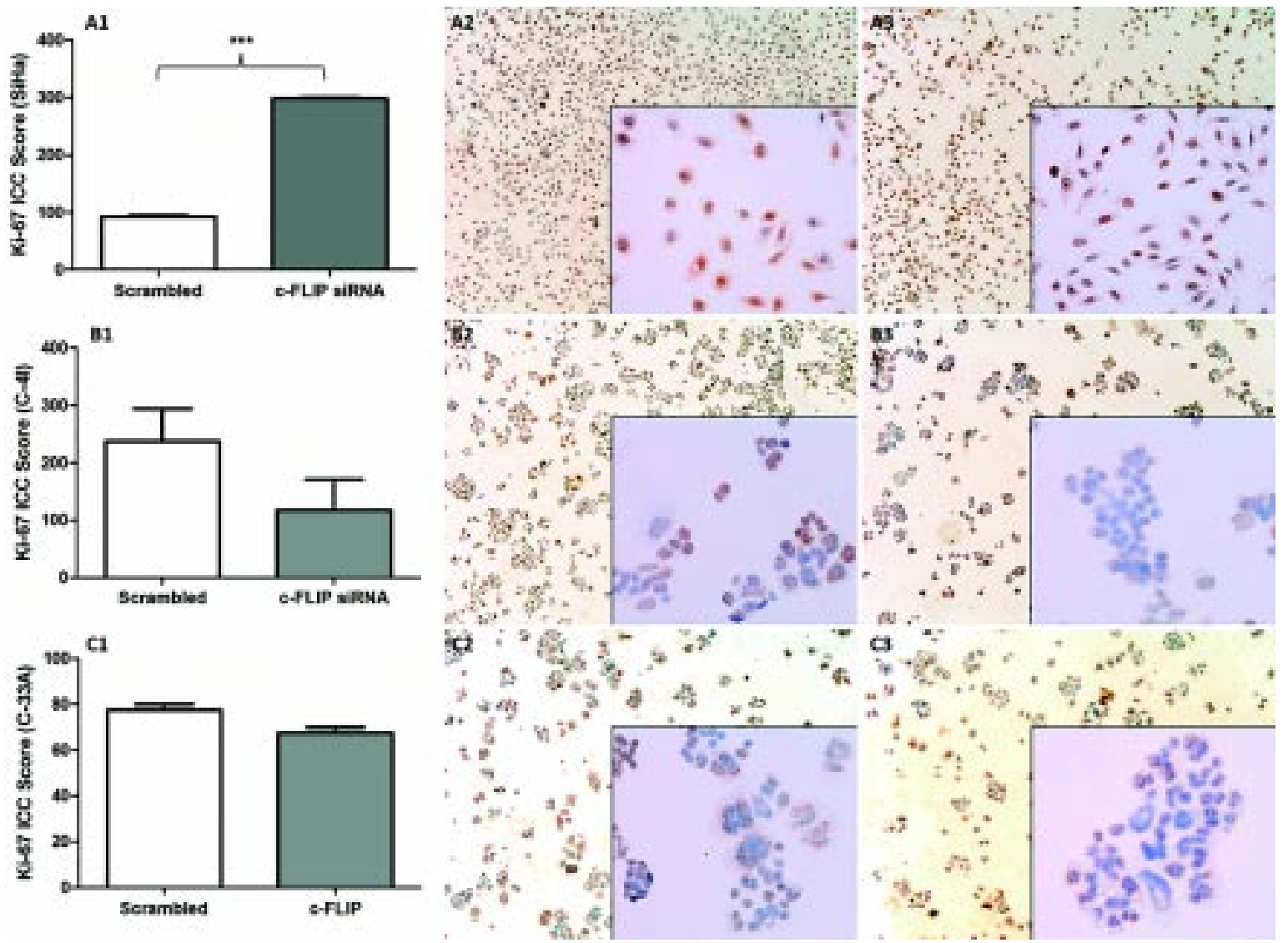

Fig. 4. Ki-67 Immunocytochemistry analysis in c-FLIPL knockdown cells compared with scrambled. (A1) Ki-67 score in $\mathrm{SiHa}$ transfected cell line compared with scrambled; (A2) Ki-67 staining in SiHa siRNA negative control cells; (A3) Ki-67 staining in SiHa c-FLIPL siRNA cells. (B1) Ki-67 score in C-4I transfected cell line compared with scrambled; (B2) Ki-67 staining in C-4I siRNA negative control cells; (B3) Ki-67 staining in C-4I c-FLIPL siRNA cells. (C1) Ki-67 score in C-33A transfected cell line compared with scrambled; (C2) Ki-67 staining in C-33A siRNA negative control cells; (C3) Ki-67 staining in C-33A c-FLIPL siRNA cells. Magnification used was 20X. Inserts were acquired with at a higher magnification (40X). ${ }^{* * *}=\mathrm{P}<0.001$ as compared with control; Mann-Whitney U test.

Proliferation of cervical cancer cell lines. C-4I and C$33 \mathrm{~A}$ cells showed a lower Ki-67 expression in c-FLIP knockdown cells. However, no significant differences were found (Fig. 4). On the other hand, siRNA c-FLIP-transfected $\mathrm{SiHa}$ cells showed a high expression of Ki-67 compared with their scrambled control $(\mathrm{P}<0.0001)$.

All c-FLIP-transfected cell lines showed a lower PCNA expression compared with their respective scrambled control cells; however, only C-33A showed a significant difference $(\mathrm{P}<0.01)$ (Fig. 5).

c-FLIP inhibition increases DNA fragmentation in cervical cancer cell lines. TUNEL-based method was performed to detect DNA fragmentation, which is a marker of apoptosis. Cell subpopulations showed that c-FLIP knockdown in $\mathrm{SiHa}$ cells $(\mathrm{P}<0.05), \mathrm{C}-4 \mathrm{I}(\mathrm{P}<0.01)$ and $\mathrm{C}-33 \mathrm{~A}(\mathrm{P}<0.05)$ cell lines led to an increased level of DNA fragmentation compared with scrambled siRNA-treated cells (Fig. 6).

\section{DISCUSSION}

The c-FLIP gene is overexpressed in several forms of cancer, such as colon carcinoma, gastric carcinoma and lymphomas, among others (Yang). In this study, c-FLIPL knockdown in cervical uterine cancer cell lines was shown to be involved in proliferation and apoptosis of cervical cancer cell lines.

Significant differences were observed in $\mathrm{SiHa}$ and C-4I cell viability. c-FLIPL knockdown showed a higher viability of SiHa and C-4I compared with scrambled cells, 

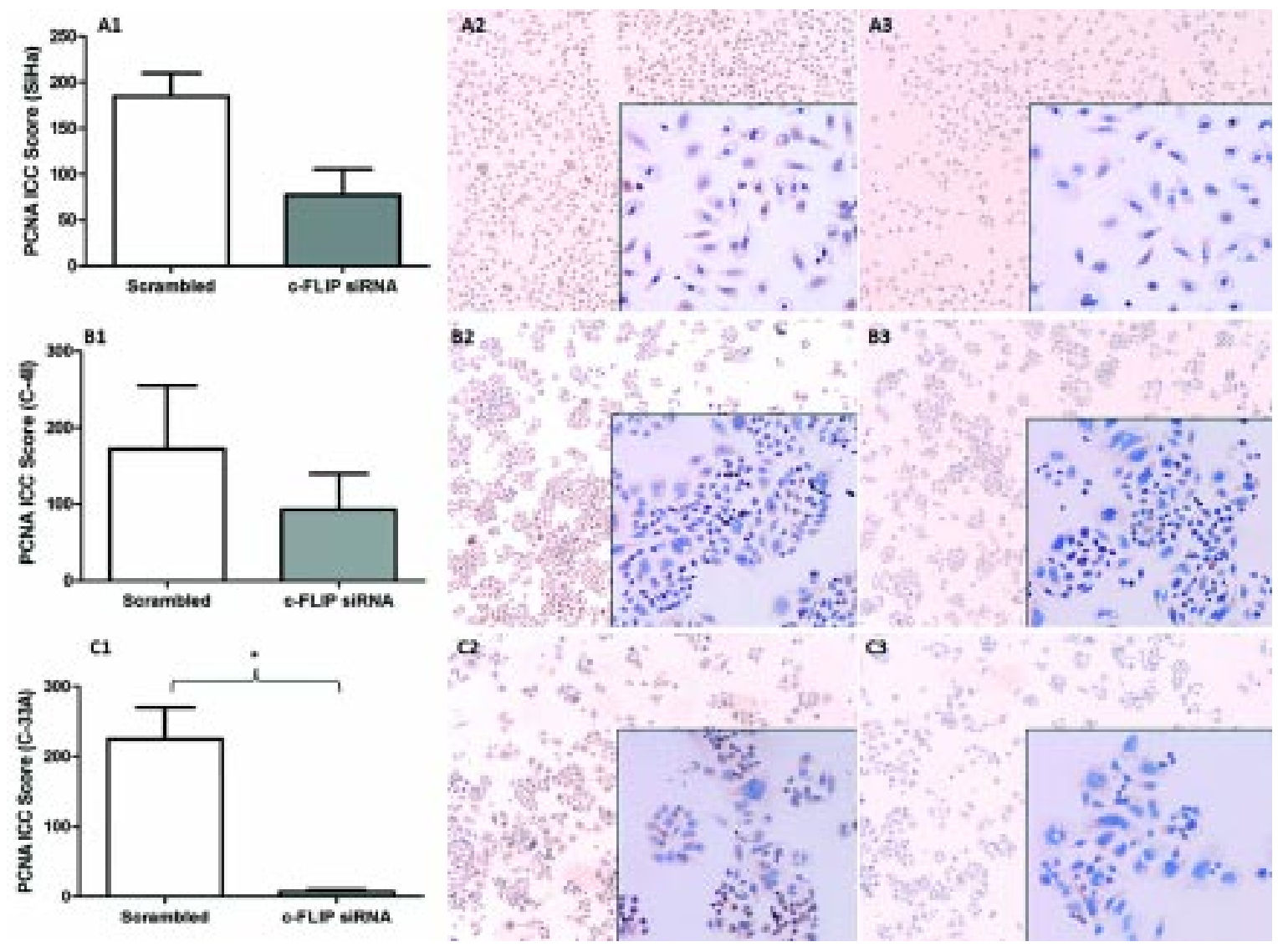

Fig. 5. PCNA Immunocytochemistry analysis in c-FLIPL knockdown cells compared with scrambled. (A1) PCNA score in SiHa transfected cell line compared with scrambled; (A2) PCNA staining in SiHa siRNA negative control cells; (A3) PCNA staining in SiHa c-FLIPL siRNA cells. (B1) PCNA score in C-4I transfected cell line compared with scrambled; (B2) PCNA staining in C-4I siRNA negative control cells; (B3) PCNA staining in C-4I c-FLIPL siRNA cells. (C1) PCNA score in C-33A transfected cell line compared with scrambled; (C2) PCNA staining in C-33A siRNA negative control cells; (C3) PCNA staining in C-33A c-FLIPL siRNA cells. Magnification used was 20X. Inserts were acquired with at a higher magnification (40X). * ${ }^{*} \mathrm{P}<0.05$, as compared with control; Mann-Whitney U test.

opposed to published data for other cell lines (Okano et al., 2003; Sharp et al.; Kavuri et al., 2011; Zaitseva et al., 2011). One explanation for that, is because the viability assay is correlated with cellular activity, the increased viability of knockdown cells could be related to cellular proliferation or a cellular response to transfection, especially for $\mathrm{SiHa}$ and C-4I cell lines. Also, it is important to consider technical limitations of this assay, such as type of culture, medium used, type of serum, $\mathrm{pH}$ and length of exposure to light, according to manufacturer (Promega).

SiHa siRNA c-FLIP cells showed high expression of $\mathrm{Ki}-67$, thereby confirming higher proliferation activity in knockdown cells compared with their siRNA control. Additionally, the rate of apoptosis was also higher. However, no significant differences were observed in PCNA expression between the c-FLIP and scrambled siRNA-transfected $\mathrm{SiHa}$ cells. Otherwise, C-4I knockdown cells showed a higher viability and an elevated rate of apoptosis compared to scrambled control cells. Nevertheless, there were no significant differences in Ki-67 and PCNA expression. There were no significant differences in C-33A viability after transfection, but there was a clear diminution of PCNA expression and apoptosis increase.

It is known that $\mathrm{Ki}-67$ is a nuclear cell proliferation marker in cancer (Beresford et al., 2006). Ki-67 expression varies throughout the different cell cycle phases. This protein is expressed by the cells during G1, S, G2, and M phases but not during G0. Ki-67 levels are low in the G1 and $\mathrm{S}$ phases and rise to their peak level during mitosis. In the mitotic phase (anaphase and telophase), there is a decrease in Ki67 expression (Yerushalmi et al., 2010). PCNA is a subunit of DNA polymerase-delta and is essential 

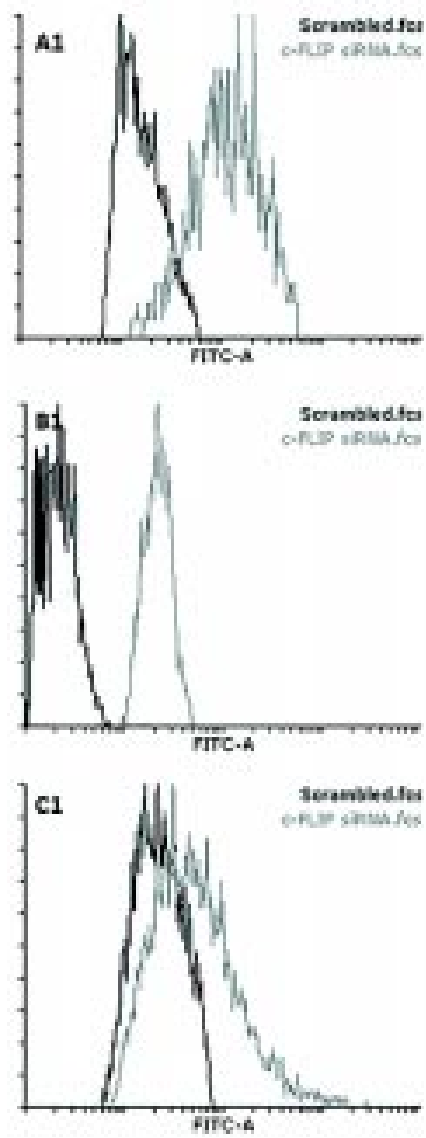
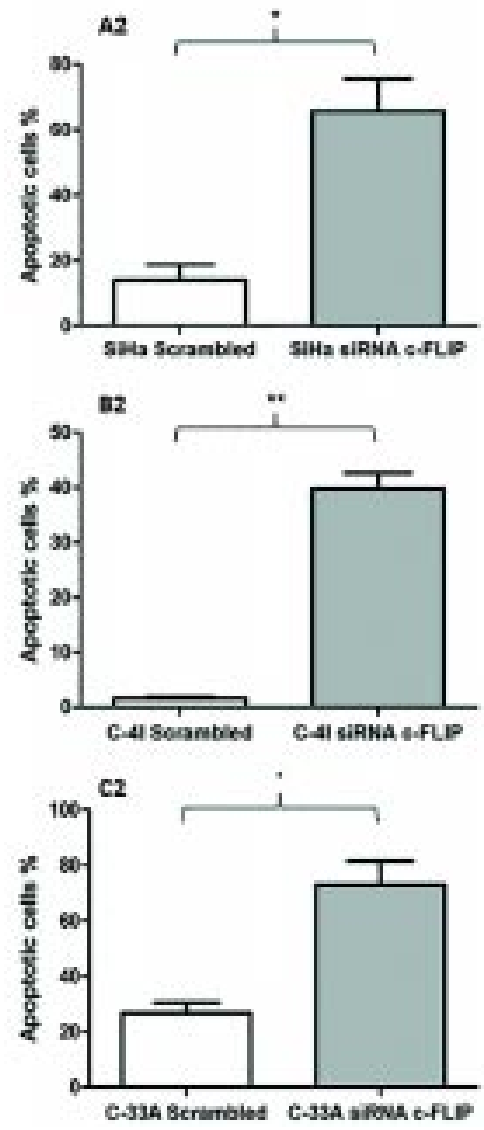

Fig. 6. Effect of c-FLIPL knockdown on apoptosis assay in (A) SiHa (B) C-4I and (C) C-33A. For an appropriate analysis, autofluorescence, negative and positive controls for each cell lines were included. Apoptosis rate in c-FLIPL siRNA transfected cells were compared against scrambled. $*=\mathrm{P}<0.05 ; * *=\mathrm{P}<0.01$, as compared with control; t-student test. for DNA replication and DNA repair (Zacchetti et al., 2003). PCNA is expressed by cells in the G1, S, G2 and M phases, and it shows a low level of expression in the early G0 phase because of its long half-life of 8 to $20 \mathrm{~h}$ (Zacchetti et al.). The highest expression of PCNA occurs during the G1 and $\mathrm{S}$ phases and decreases in the G2 and M phases (Linden et al., 1992). Therefore, some SiHa knockdown cells appear to have a mitotic response to c-FLIPL inhibition (according to Ki-67 expression), while the other cells enter to apoptosis. This event could be related to the HPV-16 genome in these cells and its oncogenic proteins, which are capable of initiating proliferation and preventing apoptosis (Longworth \& Laimins, 2004). The decreased expression of PCNA in C-33A siRNA c-FLIP-transfected cells could be attributed to the cells being in the G0 state or in G2/M phases, which could explain the low PCNA score and non-differential score in Ki-67 compared with scramble.

c-FLIP participation in non-apoptotic processes was first observed in a T-cell activation study (Kataoka et al., 2000), where Jurkat T-cells overexpressing c-FLIPL generated a higher quantity of interleukin-2 compared with normal cells. Furthermore, the activation of CD3 and Fas led to a major activation of the NF-kB and ERK pathways due to c-FLIPL overexpression. As a caspase- 8 and caspase10 homolog, c-FLIPL has a conserved aspartic acid residue (Asp376). This residue is cleaved after heterodimerization of caspase-8/FLIPL in DISC, leading to the generation of two fragments: a $10 \mathrm{kDa}$ (p10) and a $43 \mathrm{kDa}$ (p43FLIPL) fragment. p43 could recruit signaling proteins, such as TRAF2 and RIP1, and activates the NF-kB pathway (Kataoka \& Tschopp, 2004). On the other hand, c-FLIPS is not capable of recruiting these proteins. Additionally, cFLIPL can trigger the ERK pathway during T-cell activation through Raf-1 interaction (Kataoka \& Tschopp).

Several studies have shown that low concentrations of c-FLIPL could increase DISC activity and apoptosis (Chang et al.; Boatright et al., 2004). A TUNEL-based assay performed in this study showed that c-FLIPL knockdown in cervical cancer cells induce DNA fragmentation compared with their respective scrambled controls. These results indicate a potential function of c-FLIPL in apoptosis in cervical cancer cells, which is consistent with other studies performed in vitro (Okano et al.; Sharp et al.; Kavuri et al.; Zaitseva et al.). 
Despite apparent contradictions in the proliferation and apoptosis results presented here, c-FLIPL has already been shown to have dual functions as a pro- or antiapoptotic protein. c-FLIPL is currently described in the literature as a regulator of apoptosis (Chang et al.; Boatright et al.; Fricker et al., 2010). In 2010 (Fricker et al.) demonstrated that c-FLIPL function is regulated by the concentrations of c-FLIPL, c-FLIPS, procaspase-8, DISC and death ligands. Fricker et al., also described a mathematical model of c-FLIPL interaction with DISC. They found that c-FLIP could increase or delay the extrinsic pathway of apoptosis depending on c-FLIP stoichiometry during interaction with DISC. Moreover, the pro- or antiapoptotic functions of c-FLIP depend on the cells under study. Also, is important to consider HPV presence in $\mathrm{SiHa}$ and C-4I, but no in C-33A. It is known that E6 proteins of HPV inhibits apoptosis promoting p53 ubiquitination and E7 binds to the retinoblastoma ( $\mathrm{Rb})$ family of tumor suppressors, and promotes proliferation (Longworth \&
Laimins). Despite, the experimental design does not contemplate experiments to relate HPV interactions with c-FLIP functions; HPV presence could have some influence in our results. There is evidence that some proteins of HPV such E2 protein has interaction with cFLIP (Wang et al., 2011). Therefore, c-FLIP expression and functions could be regulated at some levels by HPV in $\mathrm{SiHa}$ and C-4I. Otherwise, in this study there was not evaluation of c-FLIPS and c-FLIPR, therefore both isoforms could be influencing the results.

In conclusion, c-FLIPL knockdown has effects on DNA fragmentation in cervical cancer cell lines. In cell proliferation, its participation seems to be related to c-FLIPL concentration in cells and the specific cell lines under study, considering HPV infection in SiHa and C-4I cervical cells lines. However, many studies are still necessary in order to clarify the real implication of c-FLIPL in cervical carcinogenesis.

ILI, C. G.; BREBI, P.; GARCIA, P.; LEAL, P.; LOPEZ, J.; TAPIA, O.; LETELIER, P.; WEBER, H.; CASTILLO, J. \& ROA, J. C. Efectos de la inhibición de C-FLIPL en líneas celulares de cáncer de cuello uterino. Int. J. Morphol., 33(2):638-646, 2015.

RESUMEN: Cuando las variantes Short y Raji de la proteína Cellular FLICE-like inhibitory protein (c-FLIP) se encuentran sobrexpresadas son capaces de inhibir la apoptosis, mientras la función de la isoforma Long (c-FLIPL), depende de la concentración de esta molécula en las células. El objetivo de este estudio fue determinar los efectos de la inhibición de c-FLIPL en líneas celulares de cáncer de cuello uterino. Para realizar el estudio fueron utilizadas SiHa, C-4I y C-33A, líneas celulares de cáncer cervical. La expresión de c-FLIPL en estas líneas fue establecida mediante PCR en tiempo real y western blot. Posteriormente la expresión de c-FLIPL fue inhibida, mediante transfeción transiente con siRNA complementario al mRNA mensajero de c.-FLIPL. Los efectos de esta inhibición en la viabilidad celular, proliferación y apoptosis fue comparada con células transfectadas con un siRNA control (scrambled). Una vez reprimido c-FLIPL, las líneas celulares SiHa y C-4I presentaron un aumento de la viabilidad celular $(\mathrm{P}<0,05)$. Para evaluar la proliferación celular se utilizó inmunocitoquímica de los marcadores Ki-67 y PCNA. Las células SiHa transfectadas con siRNA c-FLIPL, mostraron una elevada expresión de Ki-67 ( $\mathrm{P}<0,0001)$, mientras que las células C-33A con c-FLIPL inhibido mostraron una menor expresión de PCNA ( $\mathrm{P}<0,01)$. Las tres líneas celulares con c-FLIPL reprimido mostraron un mayor nivel de apoptosis que las células control. Estos resultados sugieren que c-FLIPL puede tener efectos en la proliferación y apoptosis de líneas celulares de cáncer de cuello uterino.

PALABRAS CLAVE: Apoptosis; Proliferación; Cáncer cervicouterino; siRNA; c-FLIPL.

\section{REFERENCES}

Bénéteau, M.; Daburon, S.; Moreau; J. F.; Taupin, J. L. \& Legembre, P. Dominant-negative Fas mutation is reversed by downexpression of c-FLIP. Cancer Res., 67(1):108-15, 2007.

Beresford, M. J.; Wilson, G. D. \& Makris, A. Measuring proliferation in breast cancer: practicalities and applications. Breast Cancer Res., 8(6):216, 2006.

Boatright, K. M.; Deis, C.; Denault, J. B.; Sutherlin, D. P. \& Salvesen, G. S. Activation of caspases- 8 and -10 by FLIP(L). Biochem. J., 382 (Pt. 2):651-7, 2004.
Budd, R. C.; Yeh, W. C. \& Tschopp, J. cFLIP regulation of lymphocyte activation and development. Nat. Rev. Immunol., 6(3):196-204, 2006.

Chang, D. W.; Xing, Z.; Pan, Y.; Algeciras-Schimnich, A.; Barnhart, B. C.; Yaish-Ohad, S.; Peter, M. E. \& Yang, X. c-FLIP(L) is a dual function regulator for caspase-8 activation and CD95mediated apoptosis. E. M. B. O. J., 21(14):3704-14, 2002.

Charafe-Jauffret, E.; Tarpin, C.; Bardou, V. J.; Bertucci, F.; Ginestier, C.; Braud, A. C.; Puig, B.; Geneix, J.; Hassoun, J.; Birnbaum, D.; Jacquemier, J. \& Viens, P. Immunophenotypic 
analysis of inflammatory breast cancers: identification of an 'inflammatory signature'. J. Pathol., 202(3):265-73, 2004.

Djerbi, M.; Darreh-Shori, T.; Zhivotovsky, B. \& Grandien, A. Characterization of the human FLICE-inhibitory protein locus and comparison of the anti-apoptotic activity of four different flip isoforms. Scand. J. Immunol., 54(1-2):180-9, 2001.

Fricker, N.; Beaudouin, J.; Richter, P.; Eils, R.; Krammer, P. H. \& Lavrik, I. N. Model-based dissection of CD95 signaling dynamics reveals both a pro- and antiapoptotic role of c-FLIPL. J. Cell Biol., 190(3):377-89, 2010.

Ili, C. G.; Brebi, P.; Tapia, O.; Sandoval, A.; Lopez, J.; Garcia, P.; Leal, P.; Sidransky, D.; Guerrero-Preston, R. \& Roa, J. C. Cellular FLICE-like inhibitory protein long form (c-FLIPL) overexpression is related to cervical cancer progression. Int. J. Gynecol. Pathol., 32(3):316-22, 2013.

Irmler, M.; Thome, M.; Hahne, M.; Schneider, P.; Hofmann, K.; Steiner, V.; Bodmer, J. L.; Schröter, M.; Burns, K.; Mattmann, C.; Rimoldi, D.; French, L. E. \& Tschopp, J. Inhibition of death receptor signals by cellular FLIP. Nature, 388(6638):190-5, 1997.

Kataoka, T.; Budd, R. C.; Holler, N.; Thome, M.; Martinon, F.; Irmler, M.; Burns, K.; Hahne, M.; Kennedy, N.; Kovacsovics, M. \& Tschopp, J. The caspase-8 inhibitor FLIP promotes activation of NF-kappaB and Erk signaling pathways. Curr. Biol., 10(11):6408,2000

Kataoka, T. \& Tschopp, J. N-terminal fragment of c-FLIP(L) processed by caspase 8 specifically interacts with TRAF 2 and induces activation of the NF-kappaB signaling pathway. Mol. Cell. Biol., 24(7):2627-36, 2004.

Kavuri, S. M.; Geserick, P.; Berg, D.; Dimitrova, D. P.; Feoktistova, M.; Siegmund, D.; Gollnick, H.; Neumann, M.; Wajant, H. \& Leverkus, M. Cellular FLICE-inhibitory protein (cFLIP) isoforms block CD95- and TRAIL death receptor-induced gene induction irrespective of processing of caspase- 8 or cFLIP in the death-inducing signaling complex. J. Biol. Chem., 286(19):16631-46, 2011.

Krueger, A.; Schmitz, I.; Baumann, S.; Krammer, P. H. \& Kirchhoff, S. Cellular FLICE-inhibitory protein splice variants inhibit different steps of caspase-8 activation at the CD95 death-inducing signaling complex. J. Biol. Chem., 276(23):20633-40, 2001.

Linden, M. D.; Torres, F. X.; Kubus, J. \& Zarbo, R. J. Clinical application of morphologic and immunocytochemical assessments of cell proliferation. Am. J. Clin. Pathol., 97(5 Suppl. 1):S4-13, 1992.

Longworth, M. S. \& Laimins, L. A. Pathogenesis of human papillomaviruses in differentiating epithelia. Microbiol. Mol. Biol. Rev., 68(2):362-72, 2004.

Okano, H.; Shiraki, K.; Inoue, H.; Kawakita, T.; Yamanaka, T.;
Deguchi, M.; Sugimoto, K.; Sakai, T.; Ohmori, S.; Fujikawa, K.; Murata, K. \& Nakano, T. Cellular FLICE/caspase-8inhibitory protein as a principal regulator of cell death and survival in human hepatocellular carcinoma. Lab. Invest., 83(7):1033-43, 2003.

Sharp, D. A.; Lawrence, D. A. \& Ashkenazi, A. Selective knockdown of the long variant of cellular FLICE inhibitory protein augments death receptor-mediated caspase-8 activation and apoptosis. $J$. Biol. Chem., 280(19):19401-9, 2005.

Wang, W.; Fang, Y.; Sima, N.; Li, Y.; Li, W.; Li, L.; Han, L.; Liao, S.; Han, Z.; Gao, Q.; Li, K.; Deng, D.; Meng, L.; Zhou, J.; Wang, S. $\&$ Ma, D. Triggering of death receptor apoptotic signaling by human papillomavirus $16 \mathrm{E} 2$ protein in cervical cancer cell lines is mediated by interaction with c-FLIP. Apoptosis, 16(1):55-66, 2011.

Wang, W.; Wang, S.; Song, X.; Sima, N.; Xu, X.; Luo, A.; Chen, G.; Deng, D.; Xu, Q.; Meng, L.; Lu, Y. \& Ma, D. The relationship between c-FLIP expression and human papillomavirus E2 gene disruption in cervical carcinogenesis. Gynecol. Oncol., 105(3):571-7, 2007.

Wang, X. The expanding role of mitochondria in apoptosis. Genes Dev., 15(22):2922-33, 2001.

Yang, J. K. FLIP as an anti-cancer therapeutic target. Yonsei Med. J., 49(1):19-27, 2008.

Yerushalmi, R.; Woods, R.; Ravdin, P. M.; Hayes, M. M. \& Gelmon, K. A. Ki67 in breast cancer: prognostic and predictive potential. Lancet Oncol., 11(2):174-83, 2010.

Zacchetti, A.; van Garderen, E.; Teske, E.; Nederbragt, H.; Dierendonck, J. H. \& Rutteman, G. R. Validation of the use of proliferation markers in canine neoplastic and non-neoplastic tissues: comparison of KI-67 and proliferating cell nuclear antigen (PCNA) expression versus in vivo bromodeoxyuridine labelling by immunohistochemistry. A. P. M. I. S., 111(3):430-8, 2003.

Zaitseva, L.; Rushworth, S. A. \& MacEwan, D. J. Silencing FLIP(L) modifies TNF-induced apoptotic protein expression. Cell Cycle, 10(7):1067-72, 2011.

\section{Dirección para Correspondencia: \\ Dr. Juan C. Roa \\ Departamento de Patología \\ Escuela de Medicina \\ Pontificia Universidad Católica de Chile \\ Marcoleta 377, Séptimo Piso \\ Santiago \\ CHILE}

Email: jcroas@gmail.com

Recibido : 27-01-2015

Aceptado: 17-04-2015 